\title{
Preliminary Assessment of Healthcare Seeking Behaviour Among Users of Primary Health Care Facilities in Ilorin Metropolis, Kwara State, Nigeria.
}

\author{
Musah K.Toyin ${ }^{1}$, Kayode O.O ${ }^{2}$ \\ 1. School of Public Health Nursing, Ogun State College of Health Technology, Ilese, Nigeria. \\ 2. Department of Epidemiology and Community Health, University of Ilorin, Nigeria.
}

\begin{abstract}
Absract: Health care seeking behaviour of patients and other clients have remained an area of concern and curiosity to provider of services in primary health care centers. This study aims to identify the key and specific actions taken by the residents of Ilorin metropolis to seek care at the primary health centre(PHC) and also to assess major factors influencing it. A qualitative phenominological study using semi-structured interview and focus group discussion was adopted for the study. The researchers conducted 36 key informant interviews with users of PHC comprising male and female; 50 focus group discussions among users of PHC facility and Indepth interviews with 20 community leaders. Additonally, official PHC document were reviewed. The findings show that there is fairly functional PHC system in the study area, faced with several challenges related to accessibility of services and shortage of resources. It was recommended among others that there should be a coordinated efforts to improve infrastructure and design behavioural health promotion campaigns to inform and educate the people especially rural dwellers that the desirable health care seeking behaviour is to patronize health facilities at PHC centre first.
\end{abstract}

Keywords: Healthcare seeking behaviour, Primary health care,Ilorin metropolis

\section{Introduction}

Health care seeking behaviour has been defined as any set of actions undertaken by an individual who perceives a health problem or an illness state for the purpose of finding an appropriate remedy ${ }^{1}$. This is based on an Explanatory model which has a coherent picture of specific cultural features which relates to health seeking behaviour. These features in turn predispose an individual to certain health behaviour. The Explanatory model of a particular illness, for example, consists of signs and symptoms by which the illness is recognised prior to diagnosis. The presumed cause of the illness and prognosis can then be established ${ }^{2}$. These are in turn interpreted by individuals or significant others who proceed to address it appropriately through standard diagnostic procedure ${ }^{2,3}$.

The transition from illness to healthcare seeking behaviour can be multidimensional particularly if the illness is not life threatening. For instance, cost of medical care is a real concern to poor people in Nigeria and similar counties. Poverty and vulnerability of means of livelihood often influence people's health status and vice versa. In addition, there must be compliance with the provision of primary health care services as determined by the interactions of all people within the health care systems ${ }^{4}$. There are concerns that user fees may restrict access to health services or lead to change in healthcare seeking behaviour with its detrimental effect on the poor. It stands to reason that whatever becomes unaffordable may be inaccessible. Many other reasons have also been advanced for households' and individuals' care seeking behaviour for the treatment of different ailments. These include knowledge and duration of sickness, attitudinal pre-disposition to illness behaviour, the anticipated cost of treatment, and patient's judgement of the severity of sickness, accessibility to health facilities, socio-cultural belief, level of endemicity in the population and subtle demographic characteristics 5 .

Health is a major determinant of the socieconomic development of people. This is based on the fact that all human endeavours require sound minds in sound bodies for full realization of aspirations.

Nigeria's health indicators are very poor compare to others in Africa and the World. World Health Organization(WHO) rate Nigeria's health system 187th position out of $191^{6,7}$. Maternal Mortality in Nigeria is one of the highest in the world ${ }^{8}$. In the first five years of the millennium, maternal mortality rose by 14 percent from 704 to 800 per 100,000 live births while under five mortality rate rose from 97 to 110 per 1000, an increase of 13 percent. The major causes of these mortalities among under-five regrettably are preventable and treatable diseases like diarrhoea and pneumonia while that of maternal mortality such as haemorrhage, preeclampsia/eclampsia, sepsis and septic abortions can be predicted to a larger extent and treated at the primary healthcare centres where emergency obstetric care capacities and functions are available ${ }^{9}$.

The tertiary and secondary levels of health services consume a disproportionate share of public human resources for health whereas most of the conditions that afflict the majority of Nigerians can be handled at the 
primary health care level. Available data showed that $70 \%$ of all ailments could be treated at the primary care levels and just $20 \%$ need to get to the secondary level while $5 \%$ to the tertiary level. However, primary healthcare, which is supposed to be the bedrock of the country's health care policy, is currently catering for less than $20 \%$ of the potential patients ${ }^{9}$

Primary health incorporates preventive, promotive, rehabilitative and curative care with emphasies on prevention. For this level to thrive, the communities must be involved in the planning, implementation and evaluation of the system in line with the Alma Ata Declaration ${ }^{10}$. It is on this premise that the researchers are set to conduct a preliminary assessment of health care seeking behaviour among users of PHC facility in ilorin metropolis through focus group discussion and indepth interview.

\section{Objectives}

1. To identify the key and specific health actions taken by residents of Ilorin metropolis to seek care at the facilities.

2. To assess the major factors influencing health care seeking behaviour among users of primary health care facilities in Ilorin motropolis.

3. To group the challenges related to health care seeking behaviour in PHC facilities in ilorin metropolis

\subsection{The study area}

\section{Methodology}

The study area is Ilorin, the capital city of Kwara State. It is located on latitude $8.30^{\circ}$ North and $4.35^{\circ}$ East of the equator. It is a major gate way between Northern and Southern Nigeria. It is an important cultural and industrial centre in the middle belt zone of Nigeria ${ }^{11,12}$.

\subsection{Sampling technique}

This was done using purposeful sampling technique.

\subsection{Ethical issue and consent}

Ethical clearance was sought and granted at the three LGAs by HOD (medical). Informed consent and focus group confirmation forms were given to participants to sign prior to all interviews and discussions.

\subsection{Group setting/ composition}

The focus group discussion and in-depth interview took place in a quiet and comfortable place. This was done to allow group participants to express their views without observation by others who were not in the group. The sitting arrangement was natural (round) and this allowed the moderator, note taker and observers to have good eye contact with all the respondents.

\subsection{Data collection}

A qualitative phenominological study using semi-structured interview and focus group discussion was adopted for the study. The researchers conducted 36 key informant interviews with health officials at District and health centre levels; 50 focus group discussions among users of PHC facility and In-depth interviews with 20 community leaders. Additonally, official PHC document were reviewed. Topic covered during key informant interview included the nature of PHC components being implemented at health centre and community levels, priority health issues at community level, health services and thier mode of delivery at health centres and community levels, PHC coverage at district level and identification of patner organisations actively involved in PHC (if any) and most importantly health care seeking behaviour of users of these services.

The topics explored using focus group discussion and in-depth interviews among users of PHC facilities in the study area were based on the objectives of the study focusing on specific actions taken by residents to seek care at the facility.

\subsection{Data analysis}

All interviews and FGDs data collected were transcribed and processed using standard word processing software. A computer-assisted qualitative content analysis of the data using ATLAS-ti version 5.6.3 software was conducted to ensure a standardized and comparable analysis and interpretation of the qualitative data across the study sites. Review of documents made reference to health care seeking behaviour of the community members in LGA. 


\section{Results}

The results are presented in three broad themes: specific actions taken by users of PHC to seek care at the facilities; influencing factors; treatment preferences and challenges related to health care seeking behaviour in PHC facility in Ilorin metropolis.

\section{Specific actions taken by users of PHC to seek care at the facilities.} situation.

This theme has two subthemes; vis a vis specific actions taken in threatening and non-threatening

\section{a. Non-threatening situation}

"'I go to chemist shop to purchase drug if I have simple ailment like malaria, diarrhoea and other minor ailments". Haaaaa........ it is self medication ooo". (Key informant 4).

"'I take herbs if am sick, I hardly go to the hospital unless if it very necessary"' (key informant 2).

"'I also buy drugs to treat my child at the chemist if she has fever or coughing"' (mother 1).

\section{b. Threatening situation}

'It depends on what you mean by life threatening situation; ailment like measles and convulsion might be taken to the hospital but certainly not primary health centre because there is no doctor, at times no drugs ". (mother, 7)

\subsection{Factors influencing health care seeking behaviour among users of PHC facilities in Ilorin metropolis.} This theme had the following subthemes:

\section{a. Disease perception and attribution of causation.}

The participants voiced their opinion that: perceived succeptibility or belief about how vulnerable a person consider himself or herself to a certain illness matters in seeking care. They affirmed that some illnesses were best suited to being treated by the medical doctors, while other diseases were most suited to treatment by traditional healers. They noted that diseases such as malaria, typhoid and fever caused by 'natural causes' could best be treated by biomedicine. When they had such illnesses, they would go to hospital.

Here are a few of the summarry statements:

"'For me, I will go to the hospital if I think it is necessary" participant 14 \{man\}

"Long ago, when I was young, I was taken to a traditional healer... I had lost consciousness; I was seeing things that I could not understand, having nightmares, dreaming I was dying ..." [mother 10,].

"To have something draw your blood until you become white, or epilepsy, is when we take the child to a traditional healer to treat them." [community leader 5].

"When you feel that something is crawling in your stomach or legs, it does not require hospital treatment." [Mother, 5]

\section{b. Seeking alternatives}

Seeking medical care in clinics and other health centre is the first preference for those seeking treatment for their children. However, in cases where the child's health deteriorates or does not seem to improve, more than half of the parents the researcher talked to, decided to look for other alternatives, such as visiting a traditional or spiritual healer. Some of the responses were:

"When the child gets ill, I will first take them to hospital, until the hospital cannot manage it. When it is impossible [for the hospital to fully treat them] I will wait for the child's father and tell him 'let us go and try traditional medicine, it is now time to try traditional medicine'........." [Mother, 5]

Another parent the researcher talked to noted that when treatment seems not to work, they go for prayers to a faith healer.

"If I have gone to the doctor and received treatment and still see no improvement, then if the doctors have been unable to treat, I will go to seek prayers from a religious leader." [Father, 3]

\section{c. lack of medical doctors in PHC}

Lack of presence of medical doctor in most primary health centre prevents people from using the facility as said by virtually all the participants.

"'Why should I attend or take my child to a facility where doctors are not available most times. No doctor on call, you can't even see them at night. I will rather go to a private hospital where I am sure of been attended to by doctor(s)"'. (Mother 2) 


\section{d. No twenty-four hour service}

Some of the respondents complained about lack of twenty-four hour service in some facilities within Ilorin metropolis especially in Ilorin West as at the time of this study. Findings revealed that the staff had problems with non- payment of shift allowance by the government which is only peculiar to that local government area. Apart from this, in Ilorin East, some of the staff spoke about insecurity at night especially in Iponrin. Some of them talked about lack of rural allowance which can serve as motivating factor.

Other factors as revealed by findings are lack of adequate personnel, lack of money, bad road network, general attitudes towards health services, gender, acceptability, quality of services rendered, communication and cost among others.

\section{e. Preference for private hospitals}

Some of the respondents stated that they preferred to use private hospital because they were sure of been attended to on time and that drugs are always available. Others said that they are treated with respect and enjoy good attitude by private hospital workers.

\subsection{Challenges related to care seeking behaviour in primary health care facility in Ilorin metropolis}

The challenges observed during this study are grouped into three and are presented as follow;

a. Patient/ Client level: It was found out that limited open hours, lack of transportation, lack of doctors in some facilities, cost of care and perceived poor quality of service pose a lot of challenges in care seeking behaviour at primary health care in Ilorin metropolis.

b. Practitioner level: The findings revealed that the nurses and other community health extension workers are concerned about security /safety especially those at rural areas (hard to reach areas). Poor remuneration, lack of rural allowance among others.

c. Organizational/ Systemic level: The study found that problem of workforce shortages, poorly integrated services, inadequate equipment, failure of services to meet the needs of consumer (not equitable) among others constitutes hindrance to service utilization at PHC level in Ilorin metropolis.

\section{Discussion}

Biomedical treatment was the preferred choice but some consult herbalist and faith-based treatment . According to WHO 2002 report on traditional medicine, at least $80 \%$ of people of Africa use traditional medicine at some point in their lives ${ }^{13}$. Decision not to use PHC facilities largely depend on several factors; lack of presence of medical doctors, non-availability of essential drugs. Other studies have also revealed that lack of human and material resources as well as the lack of confidence at PHC level is responsible for this practice ${ }^{14}$. Non-availability of equipment and laboratory services in some facilities. Lack of twenty-four hour service in some health centres. preference for private and Teaching hospitals, perceived poor quality of services, poor integrated services and failure of services to meet the needs of the consumers. It was also found that socioeconomic status and proximity to health centres were not really a problem to those who participated in this study, rather, they were particular about quality of service.

\section{Conclusion /Recommendation}

The findings of this study indicate that while there is in existence a PHC structure in the study area, the implementation is however sub-optimal with poor service utilization and this has negative influence on the residents' health care seeking behaviour at PHC centres. The study also showed that there is inequitable geographical distribution of PHC services even within the same District. A comprehensive healthcare system in Nigeria therefore, has to focus more on the $65 \%$ of the rural people. There should be a coordinated effort to improve rural infrastructure and design behavioral health promotion campaigns to inform and educate the people especilly rural people that the desirable health care seeking behavior is to patronize health facilities at PHC centre first. Policy makers must understand health-seeking behavior and service use at the rural areas and give enough credence to these facts so that policies could be designed appropriately.

\section{References}

[1]. Institute of Development Studies. Mobilizing social science research to improve health. IDS Policy Briefing. Issue 23. Sussex. 2005 .

[2]. Foster, G.M. and Anderson, B.G. Medical Anthropology. John Wiley and sons Inc. USA. Kleinman, A. Patients and Healers in the context of culture. Berkeley: University of California press, 1980.

[3]. MacKian S. A review of health seeking behaviour: problems and prospects. Internal concept paper. Health Systems Development Programme, London School of Hygiene and Tropical Medicine. London. 2001. 
[4]. World Health Organization. Jakarta Declaration on Leading Health Promotion into the 21 st Century. The Fourth International Conference on Health Promotion: New Players for a New Era- Leading Health Promotion into the 21st Century. Jakarta. 1997.

[5]. World Health Organization. Mexico Ministerial Statement for the Promotion of Health. The Fifth Global Conference on Health Promotion. Health Promotion: Bridging the Equity Gap. Mexico City. 2000.

[6]. World Bank. Global burden of disease and risk factors. Washington DC, 2006.

[7]. Hausmann-Mueala S, Muela Ribera J, Nyamongo I: Health-seeking behaviour and the health system response. Disease Control Priorities Project (DCPP). Working Paper no.14; 2003.

[8]. HERFON; Proceedings of National Health Conference. Theme: 'Primary Health Care in Nigeria: Thirty years after Alma Ata. Abuja, Nigeria.

[9]. Asesegun O.F., \& Kayode T.I. National Study on essential obstetric care facilities in Nigeria. FMOH/UNFPA. 2003.

[10]. WHO-UNICEF. Primary Health Care, Report of the International Conference on Primary Health Care, WHO, Geneva. 1978.

[11]. World LingoTranslation Localization Globalization. Ilorin. Available at http://www.worldlingo.com/ma/enwiki/en/Ilorin. Last accessed on 20-3-2011

[12]. 12 Kwara State Government. Ilorin State Capital. Available at http://www.kwarastate.gov.ng/ilorin-state-capital.html. Last accessed on 20-3-2011.

[13]. WHO Traditional Medicine Strategy 2002-2005. WHO.

[14]. Akande TM. Referral System in Nigeria: Study of a Tertiary Health Facility. 2004. Annals of African medicine 3 (3): 130-133. 